\title{
Fracture patterns in midshaft clavicle fractures
}

\author{
Alexander Van Tongel, Lieven De Wilde, Yasunori Shimamura, Jan Sijbers, Toon Huysmans
}

From the Department of Orthopaedic Surgery and Traumatology, Ghent University Hospital, Gent, Belgium

Current classifications of midshaft clavicle fractures are based on radiography. The aim of the study was to evaluate the fracture pattern of clavicle fractures using 3-dimensional computed tomography (3D CT). A retrospective analysis was performed on $\mathrm{CT}$ scans of 65 acute clavicle fractures. Using quantitative 3D CT reconstruction techniques, the fracture of the clavicle was virtually reduced. Based on these reconstructions, a group-based fracture heat map and small fragment heat map, and the location of the most common fracture line were determined. Also, the direction and amount of displacement were evaluated. Three fracture patterns could be distinguished. The primary fracture line in type 1 is going from posteromedial to anterolateral and located between $50 \%$ and $68 \%$ of the clavicle's length. In type 2 , a transverse fracture line is located around $55 \%$, and in type 3, a superolateral to inferomedial line is located between $47 \%$ and $56 \%$. Wedged fracture fragments can be seen in types 1 and 2 and are mainly situated inferiorly. The displacement is similar in all types, but the main direction of displacement is specific for the different types (posterior, anterior, inferior). We can conclude that several fracture patterns can be seen in clavicle fractures. Most fractures are located laterally at the midshaft of the clavicle. Wedged segments are mainly located inferiorly, and at the posterior part of the clavicle, no comminution is ever seen. The direction of displacement depends on the fracture pattern.

Keywords : midshaft clavicle fracture ; 3D reconstruction ; displacement ; fracture pattern.

No benefits or funds were received in support of this study. None of the authors have a conflict of interest.

\section{INTRODUCTION}

Approximately $2 \%$ to $5 \%$ of all fractures in adults involve the clavicle. More than two-thirds of these injuries occur at the clavicle's diaphysis, and these injuries are more likely to be displaced compared to medial and lateral third fractures. $(1,2)$ Several classification systems have been developed for midshaft clavicle fractures, with Robinson's classification and the AO classification most commonly used. In these classifications, displacement and comminution are the two most important variables, and these variables have

\footnotetext{
Alexander Van Tongel ${ }^{1}$, M.D. Ph.D

Lieven De Wilde ${ }^{1}$, M.D. Ph.D.

Yasunori Shimamura²,

Jan Sijbers ${ }^{3}, \mathrm{PhD}$,

Toon Huysmans ${ }^{3,4}, \mathrm{PhD}$

${ }^{\prime}$ Department of Orthopaedic Surgery and Traumatology, Ghent University Hospital, Corneel Heysmanslaan 10, B-9000 Gent, Belgium.

${ }^{2}$ Okayama University Hospital, Okayama, Japan

${ }^{3}$ Imec-Vision Lab, Department of Physics, University of Antwerp, Universiteitsplein 1, B-2610 Antwerp, Belgium.

${ }^{4}$ Faculty of Industrial Design Engineering, Delft University of Technology, The Netherlands.

Correspondence : Alexander Van Tongel, Department of Orthopaedic Surgery and Traumatology, Ghent University Hospital, De Pintelaan 185, 9000 Gent, Belgium. Phone : $+32 / 9 / 332102$. Fax +32/9/3324975.

Email : Alexander.vantongel@uzgent.be

- 2021, Acta Orthopædica Belgica.
} 
been shown as prognostic factors for nonunion. (3-5) However, these classifications are based on radiography. The fracture line's correct location and the direction of displacement of the lateral part compared to the medial part have not been evaluated.

The usefulness of fracture mapping has undoubtedly contributed to the understanding and treatment of mapped fractures, including the tibia plateau (6), olecranon (7) and scapula (8). An improved understanding of fracture morphology, based on computed tomography (CT) and quantitative 3-dimensional CT (3D CT) analysis of the clavicle, might guide decision-making and implant development. The aim of the study was to evaluate the fracture pattern of clavicle fractures using $3 \mathrm{D}$ CT.

\section{MATERIAL AND METHODS}

A retrospective analysis was performed on CT scans of acute clavicle fractures. The ethical committee has reviewed this study, and a positive advice was given for this protocol on 17/06/14. Ethics committee UZ Ghent, Chairman: Prof. Dr.Rubens Registration number: B670201420879. Informed consent was given by all patients.

A CT scan was performed in case of polytrauma or operative indication (patients who wanted a quicker recovery). The patient was positioned in the supine position with the hand situated on the belly.

In this study CT images are used that were obtained by a Somatom Volume Zoom - Siemens CT (Siemens CT ; Siemens, Erlangen, Germany).

Both shoulders and clavicles were scanned simultaneously because the clavicle fracture cannot be positioned centrally in the CT gantry.

The pixel size and the slice increment of the images were standardized and were maximum of $0.977 \mathrm{~mm}$ and $1.5 \mathrm{~mm}$, respectively.

First, all clavicle were $3 \mathrm{D}$ reconstructed in the software program Mimics ${ }^{\circledR}$ and analyzed according to the AO classification in simple, wedged, or complex (9).

Also, the contralateral clavicle was 3D reconstructed. Using the mirrored contralateral side as a template, the fractured clavicle was anatomically reduced.

Next, the 3D CT images were automatically segmented by morphological image-processing operations. From the obtained segmented images, the outer boundary surface of each clavicle was extracted using the marching cubes algorithm (10). All right clavicles were mirrored with respect to the sagittal plane and thereby brought into the left clavicle's coordinate space. The resulting reduced clavicles were taken as the input for a processing pipeline, built with Python and VTK (Python -VTK ; Kitware, NY, USA). With this technique, all clavicles and fracture lines were reduced to one clavicle model, and we were able to obtain a groupbased fracture heat map and small fragment heat map (11-13) (Fig. 1)

The fracture line distribution was evaluated on the clavicle's superior view, and the primary fracture line was evaluated. The primary fracture line was defined as a continuous fracture line from superior to inferior.

Based on three repetitive patterns, three types were proposed : 1) a primary fracture line going from posteromedial to anterolateral (Type 1), 2) transverse fracture line (Type 2), and 3) a primary fracture line going from superomedial to inferolateral (Type 3). Next, the accessory fracture lines were evaluated in the three different groups to evaluate the wedge fracture fragments.

The next goal was to describe the fracture's correct location as a percentage of the complete clavicle length $(0 \%$ medial $-100 \%$ lateral $)$ on the anterior, posterior, superior, and inferior surface curve (12) (Fig 2).

Using the data analysis tool from paraview (Plot on Sorted Lines), the location of the highest density of the heat map on the 4-surface curve was analyzed and described using the centerline percentage as $\mathrm{X}$-axis. (Fig 3)

Also, the location of the wedged fracture part was analyzed (Fig 4).

Finally, if there was a displacement of the fracture on the original pre-reduced $3 \mathrm{D}$ reconstructed clavicle fractures, the distance $(\mathrm{mm})$ between the posterosuperior part of the lateral part and the medial part of the two main fragments was measured. Also, 


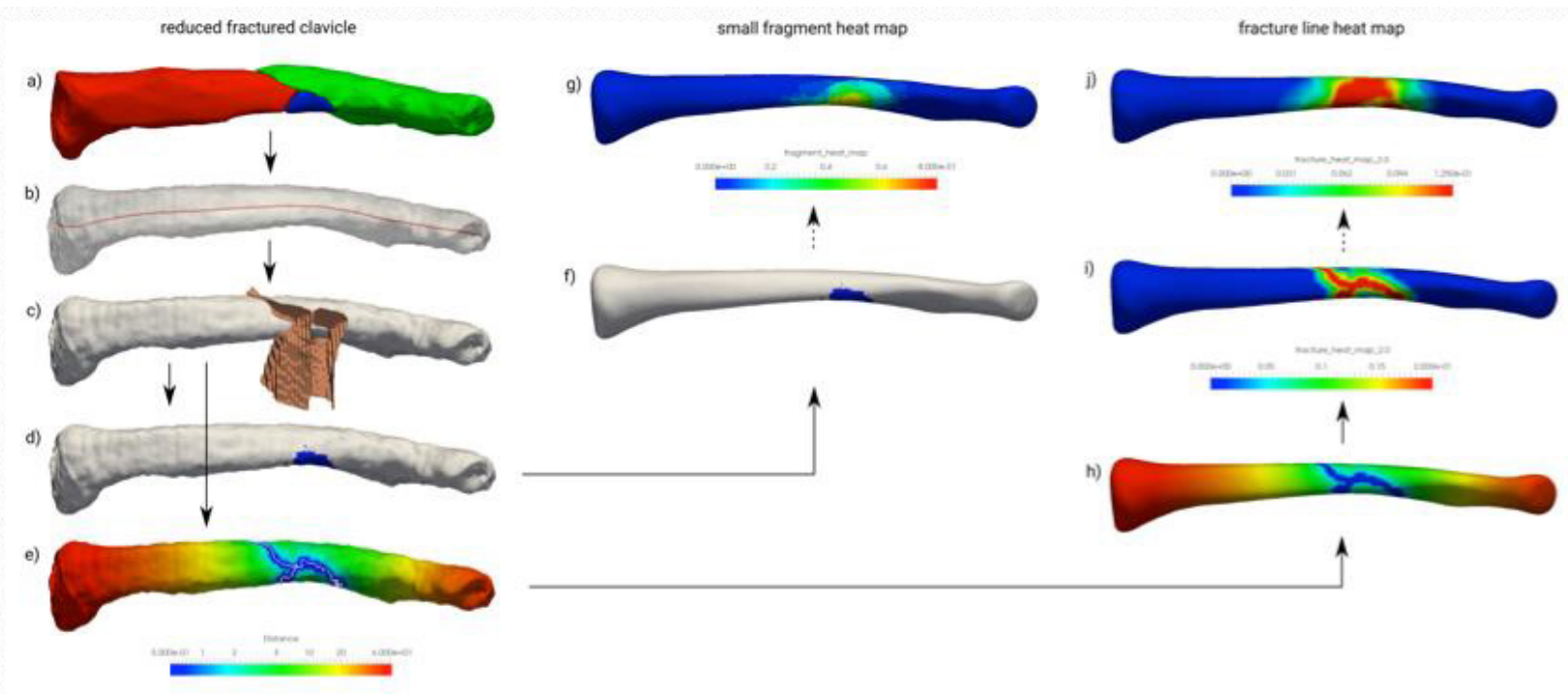

Figure 1. - In the first column, the process of obtaining a small fragment location map and a fracture distance map for an individual bone is visualized. First, a statistical shape model is fit to (a) the ensemble of the fracture fragments, resulting in (b) an approximation of the bone before the fracture from which the centerline can be derived (red line). (c) A fragment separation surface is computed on this surface that allows to separate (d) the region of the small fragments and (e) to calculate the fracture distance map. In the second column, it is shown how the obtained small fragment map is (f) mapped to a common space, namely that of the mean clavicle shape, and $(\mathrm{g})$ how a group-based fragment map is obtained by averaging the individual maps for all bones in the group. In the third column, the fracture distance map is (h) mapped to the mean clavicle and (i) converted to a heat map and finally (j) averaged to a group-based fracture heat map.

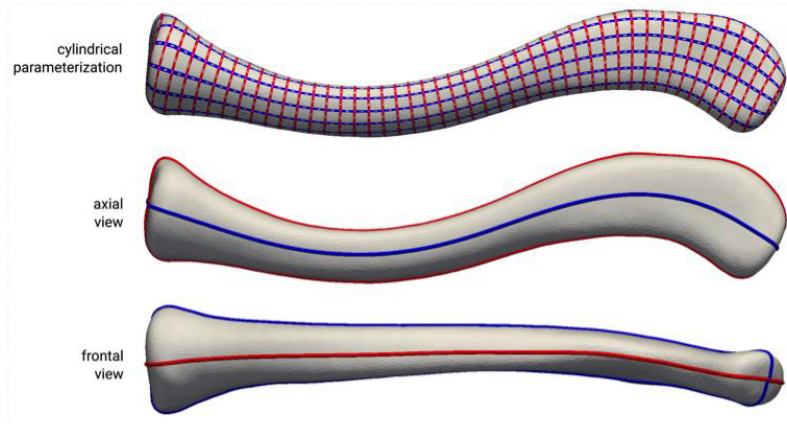

Figure 2. - Angular subdivision of the average clavicle surface in a superior/inferior (red curve) and anterior/posterior (blue curve), derived from the cylindrical parameterization.

the direction of the displacement was evaluated using the line connecting the posterosuperior part of the lateral part and medial part of the two main fragments described as mainly anterior, inferior, posterior, or superior based on the axial plane (through the anterior and posterior surface curves) and frontal plane (through the superior and inferior surface curves) (Fig 5).

\section{RESULTS}

There were 65 clavicle fractures ( 65 patients) evaluated, 38 shoulders from male patients, and 27 from female patients. The overall mean age is 54 years (from 29 up to 73 years). In total, 30 non-comminuted and 35 wedged fractures were evaluated (Table 1). No segmental fractures were in our database.

As described, three different patterns, based on the primary fracture line's direction, were seen (Fig 3).

In the first pattern, the primary fracture line goes from posteromedial to anterolateral (Type 1) (8 non-comminuted, 17 wedged). In case of a wedged fracture, the butterfly fragments are positioned anterolateral and inferior from the primary fracture line (Fig 4a). There is no comminution at the posterior part of the clavicle. On average, the most medial part of the fracture is located posteriorly between 50 and $54 \%$ and most lateral anteriorly between $54-68 \%$ (Table 1 ). In the case 

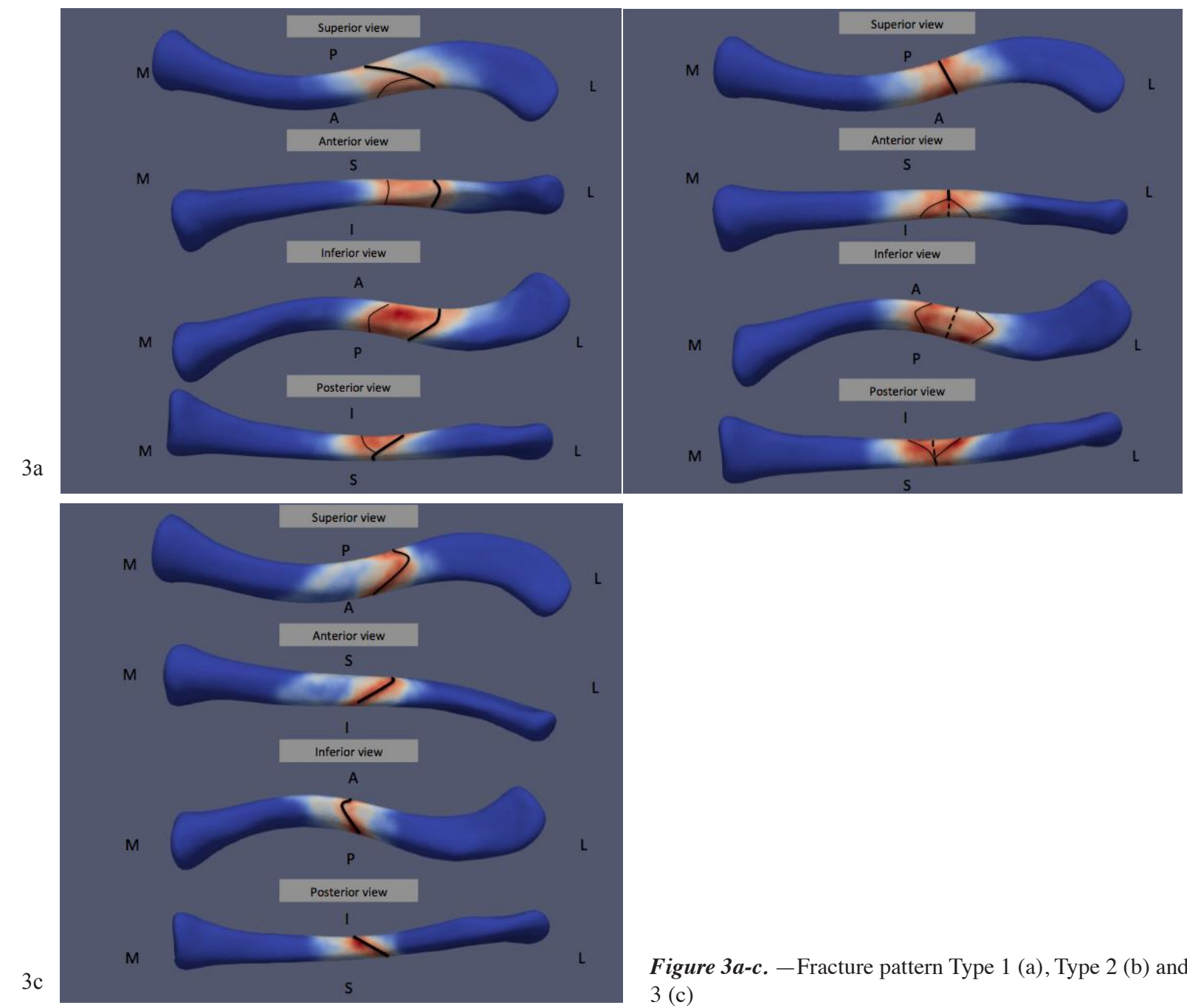

Figure 3a-c. - Fracture pattern Type 1 (a), Type 2 (b) and Type 3 (c)
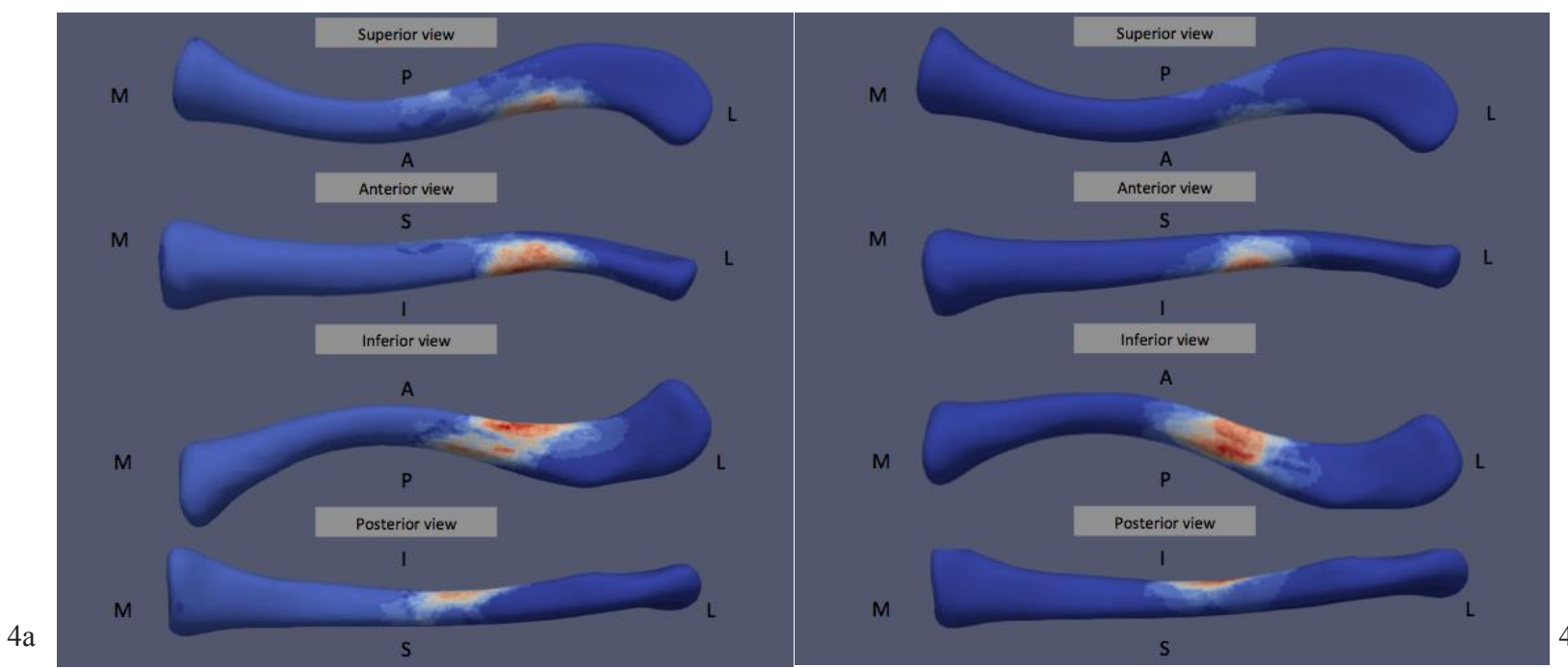

Figure 4a-b. - Wedged fragments Type 1 (a) - Type 2 (b). 


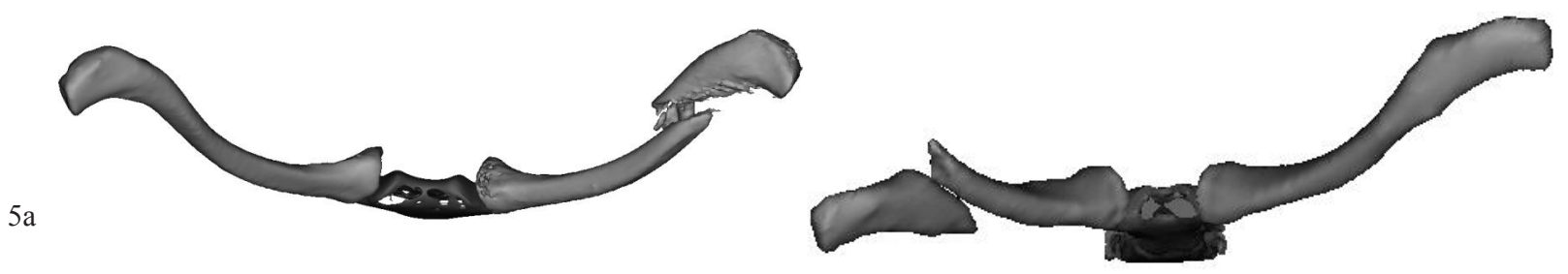

Figure 5a-b. - Posterior displacement lateral part Type 1 (a) - anterior displacement lateral part Type 3 (b)

Table 1. - Demographics

\begin{tabular}{|c|c|c|c|c|c|c|}
\hline $\begin{array}{l}\text { Fracture } \\
\text { pattern }\end{array}$ & Type & number & displaced & $\begin{array}{l}\text { distance } \\
(\mathrm{mm})\end{array}$ & direction (transversal) & direction (frontal) \\
\hline \multirow[t]{3}{*}{1} & total & 25 & 17 & 14 (SD 3) & $\begin{array}{c}\text { posterior }(15 / 17) \text { - no displacement } \\
(2 / 17) \text { - anterior }(0 / 17)\end{array}$ & $\begin{array}{c}\text { inferior }(15 / 17) \text { - no displacement } \\
(2 / 17) \text { - superior }(0 / 17)\end{array}$ \\
\hline & $\begin{array}{l}\text { non } \\
\text { comminuted }\end{array}$ & 8 & 3 & $14(\mathrm{SD} 1)$ & $\begin{array}{c}\text { posterior }(3 / 3) \text { - no displacement } \\
(0 / 3) \text { - anterior }(0 / 3)\end{array}$ & $\begin{array}{c}\text { inferior }(2 / 3) \text { - no displacement } \\
(1 / 3) \text { - superior }(0 / 3)\end{array}$ \\
\hline & wedged & 17 & 14 & 15 (SD 4) & $\begin{array}{c}\text { posterior }(12 / 14) \text { - no displacement } \\
(2 / 14) \text { - anterior }(0 / 14)\end{array}$ & $\begin{array}{c}\text { inferior }(13 / 14) \text { - no displacement } \\
(1 / 14) \text { - superior }(0 / 14)\end{array}$ \\
\hline \multirow[t]{3}{*}{2} & total & 35 & 27 & $16(\mathrm{SD} 4)$ & $\begin{array}{c}\text { posterior }(6 / 27) \text { - no displacement } \\
(7 / 27) \text { - anterior }(14 / 27)\end{array}$ & $\begin{array}{c}\text { inferior }(21 / 27) \text { - no displacement } \\
(5 / 27) \text { - superior }(1 / 27)\end{array}$ \\
\hline & $\begin{array}{l}\text { non } \\
\text { comminuted }\end{array}$ & 17 & 12 & $\begin{array}{l}15(\mathrm{STD} \\
5)\end{array}$ & $\begin{array}{c}\text { posterior }(1 / 12) \text { - no displacement } \\
(3 / 12) \text { - anterior }(8 / 12)\end{array}$ & $\begin{array}{c}\text { inferior }(8 / 12) \text { - no displacement } \\
(4 / 12) \text { - superior }(0 / 12)\end{array}$ \\
\hline & wedged & 18 & 15 & $17(\mathrm{SD} 4)$ & $\begin{array}{c}\text { posterior }(5 / 15) \text { - no displacement } \\
(4 / 15) \text { - anterior }(6 / 15)\end{array}$ & $\begin{array}{c}\text { inferior }(13 / 15) \text { - no displacement } \\
(1 / 15) \text { - superior }(1 / 15)\end{array}$ \\
\hline \multirow[t]{3}{*}{3} & total & 5 & 5 & $13(\mathrm{SD} 4)$ & $\begin{array}{c}\text { posterior }(0 / 5) \text { - no displacement } \\
(0 / 5) \text { - anterior }(5 / 5)\end{array}$ & $\begin{array}{c}\text { inferior }(2 / 5) \text { - no displacement } \\
(3 / 5) \text { - superior }(0 / 5)\end{array}$ \\
\hline & $\begin{array}{l}\text { non } \\
\text { comminuted }\end{array}$ & 5 & 5 & $13(\mathrm{SD} 4)$ & $\begin{array}{c}\text { posterior }(0 / 5) \text { - no displacement } \\
(0 / 5) \text { - anterior }(5 / 5)\end{array}$ & $\begin{array}{c}\text { inferior }(2 / 5) \text { - no displacement } \\
(3 / 5) \text { - superior }(0 / 5)\end{array}$ \\
\hline & wedged & 0 & - & - & & \\
\hline
\end{tabular}

of displacement (3 non-comminuted, 14 wedged), the direction of displacement of the lateral part is mainly posteroinferior compared to the medial part (Fig 5a). The average displacement was $14 \mathrm{~mm}$ (between 5 and $21 \mathrm{~mm}$ ).

In the second pattern, the primary fracture line is transverse superior, anterior and posterior at $55 \%$ of the length of the clavicle (Fig $3 \mathrm{~b}$ ), and in case of a wedged fracture, this is located inferior and almost equally distributed medial and lateral compared to the primary fracture line (between $49 \%$ and $62 \%$ ) (17 non-comminuted, 18 wedged) (Type 2) (Fig 4b). In case of displacement, there is a difference between non-comminuted (17 cases) and wedged (18). (Table 1) In non-comminuted (12/17), the lateral part is displaced more anteriorly, and in wedged fractures (16/18), the displacement is more inferiorly. The average displacement was $16 \mathrm{~mm}$ (between 7 and $23 \mathrm{~mm}$ ).
In the third fracture line, the primary fracture line goes from superolateral to inferomedial (5 cases) (Fig 3c) (Type 3). There are no wedged fractures in this group. On average, the most medial part of the fracture is $47 \%$, and the most lateral part at $56 \%$. In all cases, the lateral part of the fracture is displaced anteriorly (Fig 5b). The average displacement was $12 \mathrm{~mm}$ (between 5 and $17 \mathrm{~mm}$ ).

\section{DISCUSSION}

3DCT analyses of fractures have been used and influenced our current understanding of several fractures. (7,14-16). However, to our knowledge, this is the first 3DCT reconstruction study of clavicular fractures and might help to improve our understanding of fracture morphology, patterns, and displacement and can facilitate the reduction 
techniques when surgery is done for this type of fractures.

First of all, three different patterns were seen. Next to the primary fracture line, also the direction of displacement of the lateral fragment in correlation with the medial fragment was different between the patterns. In non-comminuted fractures type 2 and 3 , the displacement is mainly anteriorly, and in type 1 fractures, the direction is posteroinferior. Currently, the amount of displacement has been described as a negative factor in the prognosis of non-operative treatment. However, as has been evaluated by Van Tongel et al. (17), the amount of displacement depends on the scapula's pro and retraction and can change in the same patient depending on his position. Not the specific amount of displacement at one moment but the difference in the amount of displacement between pro and retraction may be an indicator for the fracture's stability : if there is no difference, the fracture may be diagnosed as stable, and a stable fracture may have a higher chance of union with conservative treatment. In our opinion, the direction of displacement may also influence the difference in displacement in pro- and retraction and, as a consequence, have an influence on the fracture's stability. We propose that the direction of displacement need to be taken into account if this theory is studied.

Secondly, this is the first time that the correct location of the primary fracture line and butterfly fragments is described to our knowledge. In type 1 , the fracture line is situated with the most medial point at $50 \%$ and its most lateral point at $68 \%$. In type 2, the superior side of the fracture line is situated at $55 \%$ of the clavicle. This means that the curve of the anatomical pre-contoured plate, which is to be used at its midpoint, probably will not fit adequately if the surgeon centers the plate is at the middle of the real fracture $(11,18)$. Only in patients with type 3 fractures can the pre-contoured plate be correctly positioned at the middle of the clavicle.

The most common location of the butterfly fragment depends on the fracture pattern. Theoretically, butterfly fracture results from combined bending and compression (19). Bending load causes the fracture to fail in tension producing a transverse crack, but as the crack progresses and the remaining intact bone weakens, it starts to fail in compression, causing an oblique (shear) fracture line. As the failing bone ends are driven together, a third fragment, the butterfly, may result as the oblique fragment splits off. The formation of a butterfly fragment depends on the timing and magnitude of the two basic applied loads, compression and bending. From a biomechanical point of view, the optimum position of the plate is situated opposite to the location of the butterfly fragment (tension side). This means that in comminuted clavicular fractures, the plate biomechanically should be positioned superiorly.

At last, in type 1, the location of the butterfly fragment is medial from the primary fracture line. This means that most bony contact can be made between the butterfly fragment and the clavicle's lateral side at the oblique fracture line. In Type 2, the butterfly fragment is equally disturbed between a medial and lateral part. This information can be helpful during open reduction and internal fixation while reducing and fixing the butterfly fragment. In this study, it is also observed that there is never a wedged fracture fragment at the posterior side. This means that in open reduction, the posterior part of both fragments can be used as a guide for the reduction of the clavicle fracture in case of wedged fracture fragments.

There are several limitations to consider in this study.

First, we did not include patients without a CT scan. CT scans are not ordered for most clavicular fractures. Therefore, our data are most applicable to the subset of patients in whom a CT scan was thought to be helpful for either ruling out other injuries or better characterizing a fragmented fracture. A next study will be needed to evaluate if the fracture pattern and displacement can also be seen on the clavicle's AP radiography. If the fracture pattern can be seen on an AP, the next step is to evaluate if this classification can be helpful to determine the chance of non-union in non-operative treatment.

At last, although not uncommon, in our studied population no patients with segmental fractures were seen. 


\section{CONCLUSION}

Several fracture patterns can be seen in clavicle fractures. Most fractures are located lateral at the midshaft of the clavicle. Wedged segments are mainly located inferiorly and at the posterior part of the clavicle no comminution is ever seen. The direction of displacement depends on the fracture pattern.

\section{REFERENCE}

1. Postacchini F, Gumina S, De Santis P, Albo F. Epidemiology of clavicle fractures. Journal of shoulder and elbow surgery / American Shoulder and Elbow Surgeons [et al]. $2002 ; 11(5):$ 452-6.

2. Nordqvist A, Petersson C. The incidence of fractures of the clavicle. Clinical orthopaedics and related research. 1994(300): 127-32.

3. Kulshrestha V, Roy T, Audige L. Operative versus nonoperative management of displaced midshaft clavicle fractures : a prospective cohort study. Journal of orthopaedic trauma. $2011 ; 25(1): 31-8$.

4. Faldini C, Nanni M, Leonetti D, Acri F, Galante C, Luciani D, et al. Nonoperative treatment of closed displaced midshaft clavicle fractures. Journal of orthopaedics and traumatology : official journal of the Italian Society of Orthopaedics and Traumatology. 2010 ; 11(4) : 229-36.

5. Brinker MR, Edwards TB, O'Connor DP. Estimating the risk of nonunion following nonoperative treatment of a clavicular fracture. The Journal of bone and joint surgery American volume. 2005 ; 87(3) : 676-7 ; author reply 7.

6. McGonagle LA-Ohoo, Cordier T, Link BC, Rickman MS, Solomon LB. Tibia plateau fracture mapping and its influence on fracture fixation. (1590-9999 (Electronic)).

7. Lubberts B, Janssen SJ, Mellema JJ, Ring D. Quantitative 3-dimensional computed tomography analysis of olecranon fractures. J Shoulder Elbow Surg. 2015.

8. Armitage BM, Wijdicks CA, Tarkin IS, Schroder LK, Marek DJ, Zlowodzki M, et al. Mapping of scapular fractures with three-dimensional computed tomography. $J$ Bone Joint Surg Am. 2009 ; 91(9) : 2222-8.
9. Jones GL, Bishop JY, Lewis B, Pedroza AD. Intraobserver and Interobserver Agreement in the Classification and Treatment of Midshaft Clavicle Fractures. The American journal of sports medicine. 2014.

10. Lorensen WE, Cline HE. Marching cubes: A high resolution 3D surface construction algorithm. SIGGRAPH Comput Graph. 1987 ; 21(4) : 163-9.

11. Bernat A, Huysmans T, Glabbeek FV, Sijbers J, Gielen J, Van Tongel A. The anatomy of the clavicle : A Threedimensional Cadaveric Study. Clin Anat. 2013.

12. Huysmans T, Sijbers J, Verdonk B. Automatic construction of correspondences for tubular surfaces. IEEE Trans Pattern Anal Mach Intell. 2010 ; 32(4) : 636-51.

13. Bærentzen JA, Aanaes H. Signed distance computation using the angle weighted pseudonormal. IEEE Transactions on Visualization and Computer Graphics. 2005 ; 11(3) : 243-53.

14. Mellema JJ, Janssen SJ, Guitton TG, Ring D. Quantitative 3-dimensional computed tomography measurements of coronoid fractures. J Hand Surg Am. 2015 ; 40(3) : 526-33.

15. Patzold R, Friederichs J, von Ruden C, Panzer S, Buhren V, Augat $\mathbf{P}$. The pivotal role of the coronal fracture line for a new three-dimensional CT-based fracture classification of bicondylar proximal tibial fractures. Injury. 2017.

16. Scheinfeld MH, Dym AA, Spektor M, Avery LL, Dym RJ, Amanatullah DF. Acetabular fractures : what radiologists should know and how 3D CT can aid classification. Radiographics : a review publication of the Radiological Society of North America, Inc. 2015 ; 35(2) : 555-77.

17. Van Tongel A, De Wilde L. To the Editor. Journal of orthopaedic trauma. $2015 ; 29(9)$ : e347-8.

18. Lambert S, Al-Hadithy N, Sewell MD, Hertel R, Sudkamp N, Noser H, et al. Computerized tomography based 3D modelling of the clavicle. Journal of orthopaedic research : official publication of the Orthopaedic Research Society. 2015.

19. Isa MI, Fenton TW, Deland T, Haut RC. Assessing Impact Direction in 3-point Bending of Human Femora : Incomplete Butterfly Fractures and Fracture Surfaces. Journal of forensic sciences. 2017. 